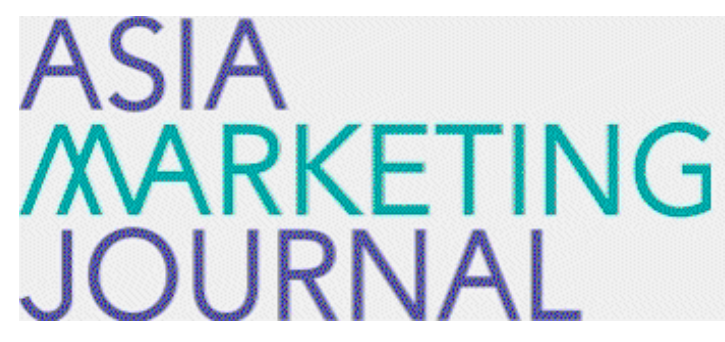

ASIA MARKETING JOURNAL

Volume 23 | Issue 2

Article 2

8-1-2021

\title{
Configurational Paths to Generating Knowledge Benefit through Customer Participation
}

Woojung Chang

University of Seoul, wchang3@uos.ac.kr

Follow this and additional works at: https://amj.kma.re.kr/journal

Part of the Marketing Commons

\section{Recommended Citation}

Chang, Woojung (2021) "Configurational Paths to Generating Knowledge Benefit through Customer Participation," Asia Marketing Journal: Vol. 23 : Iss. 2 , Article 2.

Available at: https://doi.org/10.53728/2765-6500.1179

This Article is brought to you for free and open access by Asia Marketing Journal. It has been accepted for inclusion in Asia Marketing Journal by an authorized editor of Asia Marketing Journal. 


\title{
Configurational Paths to Generating Knowledge Benefit through Customer Participation*
}

\author{
Woojung Chang**
}

\begin{abstract}
Involving customers in the new product development process has been found to create knowledge benefit for the firm. However, the different roads leading to a firm's knowledge benefit through configurations of which new product development stage customers are engaged in, a firm's internal co-creation-related capabilities, and the external environment have yet to be specified. To explore the alternative configurational paths to generating knowledge benefit through customer participation, a state-of-the-art fuzzy set qualitative comparative analysis is applied to a sample of 181 new product development projects. The results reveal six different configurations to generate knowledge benefit in the new product development process and yield useful suggestions for obtaining knowledge benefit through customer participation.
\end{abstract}

Keywords: Customer participation, New product development, Knowledge benefit, Co-creation related capability, fsQCA

\section{Introduction}

Firms frequently develop new products in collaboration with customers (Morgan, Obal, and Jewell 2021). For example, Hyundai Motors involved customers in its new product development (NPD) process during about seven months to develop its $i 30 \mathrm{~N}$ line and Veloster custom fit models (Lim 2019). Customer participation in which customers actively contribute to idea generation, designing and co-developing new products, testing prototypes, and launching new products is common in a firm's innovation process (Chang and Taylor 2016; Fang 2008). According to the knowledge management perspective, customer participation is "the customer knowledge provision phenomenon whereby customers share their needs- and solution-related inputs in the firm's NPD process"

\footnotetext{
* This work was supported by the 2019 sabbatical year research grant of the University of Seoul.

** Associate Professor of Marketing, Business School, University of Seoul (wchang3@uos.ac.kr)
} 
(Chang and Taylor 2016, p. 48). Thus, customer participation is believed to provide the firm with knowledge benefits by enabling it to capture customers' knowledge related to their needs and the solutions to their needs (Nambisan 2002; Poetz and Schreier 2012).

However, all firms that engage customers in their NPD processes do not realize these knowledge benefits in reality. This is because obtaining knowledge benefits through customer participation is not merely the outcome of integrating customers in NPD but is the result of a causally complex phenomenon in which many interconnected factors simultaneously come into play. Researchers have shown that the effectiveness of customer participation hinges on the NPD stage or combination of NPD stages (i.e., ideation, development, and launch stages) in which customers are engaged (Chang 2019; Chang and Taylor 2016; Gruner and Homburg 2000). Moreover, research on knowledge management highlights the importance of a firm's ability to transfer external knowledge, integrate the knowledge with a firm's existing knowledge stock and apply it to a new product (i.e., a firm's absorptive capacity; Cohen and Levinthal 1990; Morgan, Obal, and Anokhin 2018), and efficiently and effectively coordinate the co-creation process between the NPD team and customers (i.e., a firm's coordination capability; Fang, Palmatier, and Evans 2008). Furthermore, the influence of external environmental turbulence including the complexity of customer needs, competitive intensity, and technical turbulence on the effectiveness of customer participation has been long suggested as a key factor in the creation of knowledge benefit (Morgan, Anokhin, and Wincent 2019).

In sum, a firm's acquisition of knowledge benefit through customer participation in NPD relies on the interactions of the stage in which customers participate in a firm's NPD process, a firm's internal co-creation-related capabilities (i.e., a firm's absorptive capacity and coordination capability), and external environmental turbulence (i.e., complexity of customer needs, competitive intensity, and technical turbulence). There is no single success factor leading to knowledge benefit but several paths composed of different combinations of key factors. Thus, the realization of knowledge benefit via customer participation is best understood from a configurational perspective. In this regard, the purpose of this study is to explore various configurational paths to generating knowledge benefit by considering interactions among customer participation in the NPD process, a firm's internal co-creation related capabilities, and external environmental turbulence.

Fuzzy-set qualitative comparative analysis (fSQCA) combines both a qualitative (caseoriented) and a quantitative (variable-oriented) method and identifies configurations of conditions that are necessary or sufficient for the occurrence of an outcome (Lexutt 2020; Ragin 2008; Schneider and Wagemann 2012). While 
conventional analyses such as regressions focus on examining the net effect of each variable on a given outcome, fsQCA concentrates on figuring out different equifinal combinations of conditions driving the same goal (Fiss 2011; Ragin 2008). By applying a state-of-the-art fSQCA to 181 NPD projects in which customers were involved in a firm's innovation process, this research sheds light on how firms can obtain knowledge benefit through customer participation in conjunction with a firm's internal capabilities and external environment. The results provide specific insights about how firms should incorporate customer participation when considering their own internal capabilities and the given external environment. This configurational approach is expected to provide new insights and a more accurate description of the reality about customer participation than traditional linear and additive models (Fiss 2011; Lalicic and Weismayer 2021; Zheng, Ulrich, and Sendra-García 2021).

\section{Literature Review}

This study follows a configurational approach both conceptually and methodologically. Thus, specific hypotheses are not developed, but previous literature about how the NPD stage in which customers are engaged, a firm's co-creation-related capabilities, and external environment interact is reviewed (e.g., Lexutt 2020). Figure 1 graphically demonstrates a configurational model to lead to knowledge benefit through customer participation in NPD.

〈Figure 1〉 Configurational Model
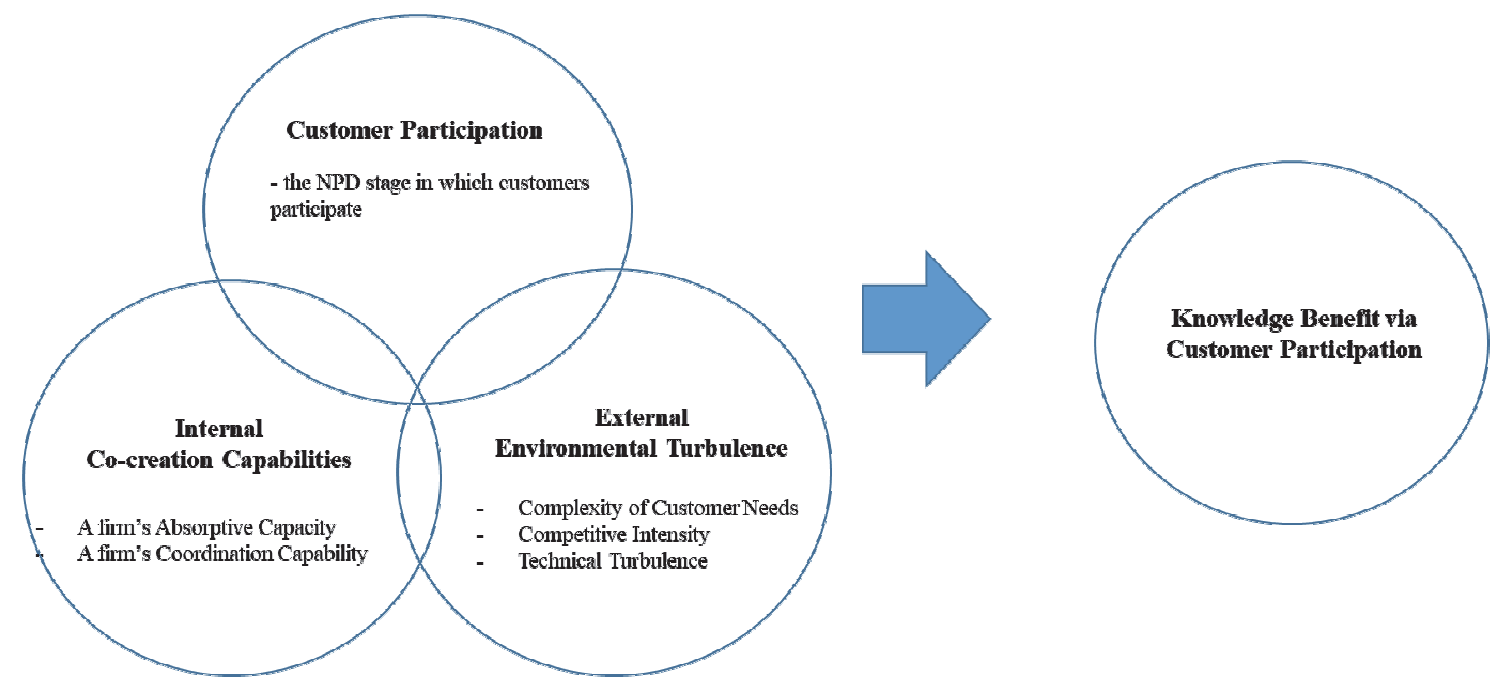

32 ASIA MARKETING JOURNAL Vol. 23 No. 02 July 2021 


\subsection{Customer Participation in Each NPD Phase and Knowledge Benefit}

Customer participation refers to the integration of customers in a firm's various NPD stages (Chang and Taylor 2016; Morgan, Obal, and Anokhin 2018). Firms can obtain various needsand solution-related knowledge through customer participation. In the ideation stage, customers actively offer their diverse ideas about untapped needs and evaluate which ideas are valuable and thus should be advanced for new products. In the development phase, customers provide solution-related knowledge regarding how firms can design and develop new products from a technical perspective. In the launch stage, customers test prototypes of new products, offer first-hand problems/ideas while using the new product, and contribute to inputs about how the proposed new product needs to be positioned and communicated.

From the knowledge management perspective, customer participation is viewed as a firm's process to acquire needs- and solution-related knowledge from customers as external sources, transfer the knowledge to the NPD team, integrate it with the firm's extant knowledge stock, and apply the integrated knowledge to new products (De Luca and Atuahene-Gima 2007; Joshi and Sharma 2004). Thus, customer participation has been argued to give the firm knowledge benefit, defined as a firm's perceived value derived from the needs- and solution- related knowledge customers provide in the NPD process (Mahr, Lievens, and Blazevic 2014).

However, customer participation does not always lead to constructive knowledge benefit (Chang and Taylor 2016). The realization of knowledge benefit through customer participation depends largely on two factors: (1) the potential value of customer knowledge (i.e., how valuable the knowledge obtained from customers is) and (2) the difficulty of knowledge management (i.e., how difficult it is to transfer the knowledge from customers and then integrate and apply it to a new product; Chang and Taylor 2016).

The NPD stage customers are involved in is one of the variables that influence both the potential value of knowledge from customers and the difficulty of knowledge management. First, customer participation in one phase may be more valuable than in others because each NPD phase requires distinct tasks and skills and therefore customers may come up with more valuable inputs in a specific NPD stage (Chang and Taylor 2016; Gruner and Homburg 2000). Specifically, Chang and Taylor (2016) and Gruner and Homburg (2000) found that involving customers in either the ideation or launch stage promoted new product success, but engaging them in the development phase did not. Customers in the development stage may lack technical and contextual knowledge required for designing a new product, which may hinder them from bringing in valuable 
knowledge in this NPD stage. Furthermore, even though customers in the development stage offer valuable solution-related knowledge, NPD R\&D personnel's deep-rooted "notinvented-here" syndrome which shuns solutions from external sources combined with role ambiguity and conflict between customers and NPD teams can make it difficult to integrate customers' valuable knowledge and apply it to a new product (Katz and Allen 1985; Wang et al. 2020).

Recent studies have investigated the combination of NPD stages in which engaging customers creates a synergistic or destructive impact. According to Chang (2019), engaging customers continuously in the ideation and development stages or in the development and launch stages generates supplementary returns, but customer participation in both ideation and launch stages or across all the NPD stages does not drive synergistic impacts on new product market performance. The synergistic effects of certain combinations of NPD stages are explained by how much additional knowledge value can be created through integrating customers in specific combinations of NPD stages and how difficult it is to interpret, translate, and integrate knowledge from concurrent participation of customers in various NPD stages. Taken together, the NPD stage or combination of NPD stages in which customers are engaged is a critical factor to determine the knowledge benefit of customer participation.

\subsection{A Firm's Internal Co-Creation- Related Capabilities}

Researchers suggest that not only external knowledge (e.g., customer knowledge obtained through customer participation) but also internal factors such as a firm's absorptive capacity and complementary assets influence new product performance through customer participation (Morgan, Obal, and Anokhin 2018; Son, Lee, and Lee 2018). As customer participation is a series of knowledge management processes to gain customer knowledge and then transfer, integrate, and apply it to a new product, customer participation on its own only ensures that external knowledge and resources become available to the firm (Morgan, Obal, and Anokhin 2018). The crucial factor in increasing the likelihood of the external knowledge being transferred, integrated, and applied to a new product efficiently and effectively is the firm's internal co-creation-related capabilities (Morgan, Obal, and Anokhin 2018: Son, Lee, and Lee 2018). These capabilities can ease the difficulty of knowledge management and ultimately maximize the knowledge benefit from involving customers in NPD.

This study suggests that a firm's two internal co-creation-related capabilities - absorptive capacity and coordination capability - play a key role in streamlining the knowledge management process around customer participation. Absorptive capacity refers to a firm's ability to recognize 
the value of new, external knowledge, assimilate it, and apply it to commercial ends (Cohen and Levinthal 1990; Lee, Park, and Pae 2015). In the customer participation context, a firm's absorptive capacity is defined as the degree to which a firm is able to recognize the potential value of knowledge obtained from customers, integrate the valuable knowledge, and apply it to a new product efficiently and effectively (Morgan, Obal, and Anokhin 2018). Thus, firms with high absorptive capacity may be better able to find which customer idea has potential value and apply it to a new product more effectively, thereby creating greater knowledge benefit and ultimately new product success. Conversely, firms without absorptive capacity may succumb to information overload and have difficulty transferring and integrating abundant and diverse customer knowledge. In this regard, Morgan, Obal, and Anokhin (2018) noted that a firm's absorptive capacity is a necessary prerequisite for building innovative and commercially successful new products when utilizing customer participation. They also found empirical evidence of the positive moderating impact of absorptive capacity between customer participation and NPD performance.

A firm's coordination capability is proposed as another pivotal $\mathrm{Co}^{-}$creation-related capability for knowledge benefit. In the co-creation context, a firm's coordination capability refers to the extent to which a firm is able to work together with customers effectively to accomplish a collective set of tasks in the NPD process (Fang, Palmatier, and Evans 2008). Most researchers argue for a positive knowledge benefit of customer participation, but customer participation cannot create knowledge benefit or offset some of the expected benefits if the interaction between customers and NPD teams is not well coordinated or if it leads to conflict (Fang, Palmatier, and Evans 2008; Wang et al. 2020).

With regard to the potential value of knowledge, a firm's coordination capability is expected to expand the potential value of knowledge through customer participation. As firms with high coordination capability take full advantage of customers' competencies, they can increase the efficacy of the interactions between customers and NPD teams across the different NPD stages, resulting in higher knowledge benefit (Fang, Palmatier, and Evans 2008). In this regard, Fang, Palmatier, and Evans (2008) verified that enhanced coordination effectiveness mediated the relationship between customer participation in NPD and new product value.

With regard to the difficulty of knowledge management, a firm's coordination capability mitigates the difficulty of transferring, integrating, and applying knowledge from customers to a new product, thereby leading to greater knowledge benefit. As social entities work together to achieve their respective objectives, conflict is unavoidable (Wang et al. 2020). Firms with high coordination capability are 
better able to coordinate the interactions between customers and NPD teams and mitigate potential conflicts by harmonizing their differences in priorities and cultural values and looking for synergistic ways to work together (Wang et al. 2020). Consequently, a firm's coordination capability as an internal resource can contribute to increasing knowledge benefit by expanding the value of the knowledge from customers and alleviating the difficulty of knowledge management.

\subsection{External Environmental Turbulence}

Researchers suggest that the effectiveness of customer participation depends on a firm's internal capabilities as well as external environmental conditions (Fang 2008; Li, Kim, and Lee 2020; Morgan, Anokhin, and Wincent 2019). In the customer participation context, three types of environmental turbulence have been found to affect new product performance: complexity of customer needs, competitive intensity, and technical turbulence (Chang and Taylor 2016; Fang 2008; Morgan, Anokhin, and Wincent 2019).

Complexity of customer needs refers to the extent of change and predictability of customers' preference and the market (Jaworski and Kohli 1993; Morgan, Anokhin, and Wincent 2019). The literature reveals that a firm which operates in an environment with a high degree of complexity of customer needs should pursue high levels of customer participation because it helps the firm tap into customers' changing needs-related knowledge and come up with new products that fit customers' current needs better than competitors (Fang 2008; Morgan, Anokhin, and Wincent 2019).

In contrast, the efficacy of customer participation is more pronounced in the low competitive intensity context than in the high competitive intensity context (Morgan, Anokhin, and Wincent 2019). There have been counter-arguments about whether customer participation is more beneficial in a high or low competitive intensity context (Jaworski and Kohli 1993). However, the attention-based view of the firm suggests that when environmental pressure from competitors is relatively intense, firms focus their limited attention on observing and responding to competitors' actions, thereby distracting them from effectively recognizing and utilizing customer inputs through customer participation. On the contrary, in conditions of low competitive intensity, firms have available resources to focus their attention on the inputs provided by the engaged customers and therefore can maximize the knowledge benefit of involving customers in NPD. Recently, Morgan, Anokhin, and Wincent (2019) provided empirical evidence that the effect of customer participation on new service development performance is greater in the low competitive intensity condition.

Finally, technological turbulence in the $\mathrm{co}^{-}$ creation context refers to the rate and uncertainty 
of technological change in the industry (Chang and Taylor 2016). "Rapid technological change leads to expeditious product obsolescence and short windows of new product opportunity" (Chang and Taylor 2016, p. 50). In such situations, customers' solution-related knowledge helps secure prompt access to emerging technologies. Further, customers can offer inputs about their changing needs caused by rapid technological change, which helps avoid delays resulting from a mismatch between ideas and needs and promotes the quick launch of a new product (Chang and Taylor 2016). As a result, the value of engaging customers during the NPD process is greater in a more technologically turbulent environment (Chang and Taylor 2016). Taken together, the three types of external environmental turbulence affect the impact of customer participation on knowledge benefit.

In summary, a few researchers have examined the net effects on the benefit of customer participation of the NPD stage in which customers participate, a firm's internal cocreation-related capabilities, and external environmental turbulence. However, little is known about which combination of NPD stages customers should be involved in when considering the firm's current co-creation capabilities and environmental situation. The present study seeks to provide insights into "fit" or "configuration" with regard to how customers should be involved in the NPD stages in the context of given capabilities and environment.

\section{Methods}

\subsection{Data Collection}

To explore various configurational paths to expanding a firm's knowledge benefit through customer participation in NPD, NPD managers participating in a Qualtrics online panel were contacted. Among the NPD managers, those who have worked on a NPD project in which end customers have been involved to some extent to co-create new products were asked to participate in an online survey. The respondents were asked to complete the online survey with the NPD project in mind in which end customers were involved in the NPD process. In total, 202 NPD managers took part in the online survey. After responses with missing values for key variables were deleted, 181 responses were left for analysis.

The sample covers various industries and firm sizes: $35.6 \%$ of the respondents come from manufacturing, $40.1 \%$ from IT, and 18.6\% from services industries. Employing customer participation in different industries (e.g., manufacturing, IT, services) may require different types of knowledge from customers and different ways of interacting between customers and NPD teams, thereby leading to distinct levels of knowledge benefit across industries. Collecting data from various industries improves the generalizability of the research 
findings.

In terms of firm size measured by the number of full-time employees, $28.3 \%$ of the respondents work for firms with fewer than 300 full-time employees, $35.6 \%$ in firms with 300-999 employees, $25.6 \%$ in firms with 1,000-3,000 employees, and $10.6 \%$ in firms with more than 3,000 full-time employees.

The respondents had a high level of knowledge about the NPD project that they reported on. The average of the answers to the question "How would you rate your knowledge of this particular NPD project?" was $6.06(S D=0.751)$ on a scale from $1=$ very low to $7=$ very high.

\subsection{Measures}

The scales used in this study are based on empirically validated scales and adapted to the co-creation context in NPD. All the constructs except customer participation in each stage of NPD were assessed on a 7-point Likert scale anchored by $1=$ strongly disagree to $7=$ strongly agree. Specific measures and Cronbach's alpha for each variable are shown in Table 1. Knowledge benefit was assessed with four items from Im and Workman (2004) that evaluate the degree to which knowledge gained from customers in the NPD process provides novel insights and application (i.e., knowledge novelty) and the extent to which knowledge from customer participation is appropriate and useful for the particular NPD project at hand (i.e., knowledge relevance; Im and Workman 2004: Mahr, Lievens, and Blazevic 2014).

With regard to customer participation at each stage, following Fang, Palmatier, and Evans (2008), respondents answered questions about how much customers are involved in each of seven NPD activities on a 7-point scale ranging from $1=$ not at all to $7=$ a great extent. Customer participation in idea generation and concept screening activities was regarded as customer participation in the ideation stage. Involving customers in product design and engineering activities was treated as customer participation in the development phase, and engaging customers in product testing, market testing, and commercialization activities was considered as customer participation in the launch stage (Chang 2019; Chang and Taylor 2016).

A firm's absorptive capacity was assessed with five items adapted from Jayachandran, Hewett, and Kaufman (2004) which reflect a firm's ability to recognize the value of input from customers in the NPD process and apply it to a new product. Seven items adapted from Fang, Palmatier, and Evans (2008) were utilized to assess how effectively the firm-customer co-creation was coordinated (i.e., coordination capability).

Finally, to capture the various influences of environmental turbulence (Morgan, Anokhin, and Wincent 2019), two items from Jaworski and Kohli (1993) were used to gauge the 
$\langle$ Table 1〉 Measures.

\begin{tabular}{|c|c|c|}
\hline Construct & Measures & Cronbach's a \\
\hline KNOW & $\begin{array}{l}\text { - We learned something new from the interaction. } \\
\text { - Acquired ideas from the interaction were important for the new product } \\
\text { development. } \\
\text { - We learned something which complements our NPD team's weakness from the } \\
\text { interaction. } \\
\text { - Solutions developed during the interaction were later used in other projects. }\end{array}$ & 0.763 \\
\hline IDEATION & $\begin{array}{l}\text { - Idea generation: the stage at which new ideas for products are brainstormed. } \\
\text { - Concept screening: the stage at which product ideas are tested for technical and } \\
\text { commercial success. }\end{array}$ & 0.744 \\
\hline DEVELOP & $\begin{array}{l}\text { - Product design: the stage at which a firm specifies designs and development of } \\
\text { a proposed product } \\
\text { - Product engineering: the stage at which a firm's engineers work to refine the } \\
\text { design and perfect a new product }\end{array}$ & 0.841 \\
\hline LAUNCH & $\begin{array}{l}\text { - Product testing: the stage at which prospective customers evaluate test versions } \\
\text { of a proposed product } \\
\text { - Market testing: the stage at which the complete marketing plan for a proposed } \\
\text { product is tested in a small geographic area } \\
\text { - Commercialization: the stage at which a proposed new product is launched into } \\
\text { the market }\end{array}$ & 0.751 \\
\hline ABSORP & $\begin{array}{l}\text { - Our NPD team quickly recognized the usefulness of insights that customers } \\
\text { - } \text { Ouggested. } \\
\text { - Our NPD team valued insights that customers suggested. } \\
\text { - Our NPD team could easily address the new needs that customers specified. } \\
\text { suggested modification of a product or service. } \\
\text { - Our NPD team could effectively satisfy customers demands. }\end{array}$ & 0.835 \\
\hline COORD & $\begin{array}{l}\text { - Customers and the NPD team worked together very effectively to exploit unique } \\
\text { - Bpportunities. } \\
\text { - Both customers and the NPD team were always looking for synergistic ways to } \\
\text { - Customers and the NPD team coordinated our business activities very effectively. } \\
\text { - Customers and the NPD team communicated significant information effectively. } \\
\text { - Customers and the NPD team made decisions on the new product quickly. } \\
\text { - There was little conflict when customers and the NPD team made decisions on } \\
\text { the new product. } \\
\text { - Scheduling meetings or interactions with customers was easy. }\end{array}$ & 0.892 \\
\hline CUSENV & $\begin{array}{l}\text { - Customers' product preferences change quite a bit over time. } \\
\text { - Customers' tastes in the market are unpredictable. }\end{array}$ & 0.676 \\
\hline COMENV & $\begin{array}{l}\text { - Competition in our industry is intensive. } \\
\text { - In our market, we hear of a new competitive move very often. }\end{array}$ & 0.799 \\
\hline TECENV & $\begin{array}{l}\text { - The technology in our industry is changing rapidly. } \\
\text { - A large number of new product ideas have been made possible through } \\
\text { technological breakthroughs in our industry. }\end{array}$ & 0.802 \\
\hline
\end{tabular}


complexity of customer needs, two items from Moorman and Miner (1997) assessed the competitive intensity in the industry, and two items from Jaworski and Kohli (1993) measured technological turbulence in the industry.

\subsection{Fuzzy-set Qualitative Comparative Analysis}

In recent years, fsQCA has gained popularity in the fields of business and management as well as organizational research (e.g., Kollmann et al. 2021; Lalicic and Weismayer 2021; Lexutt 2020; Zheng, Ulrich, and Sendra-García 2021). A fsQCA is employed in this study to explore different configurational paths leading to knowledge benefit through engaging customers in the innovation process (Ragin 2008). Qualitative Comparative Analysis (QCA) was first proposed by Ragin in 1987. It combines both a qualitative and a quantitative method in an attempt to identify the underlying combinations of causal conditions leading to a given outcome (Ragin 2008: Woodside, Ko, and Huan 2012; Zheng, Ulrich, and Sendra-García 2021). Whereas conventional analytical approaches such as regressions focus on the net effects of the variables on the outcome variable, a QCA identifies alternative variable combinations which can produce equally successful outcomes (Lalicic and Weismayer 2021; Zheng, Ulrich, and Sendra-García 2021). Given that there are alternative ways how customer participation in
NPD, a firm's internal capabilities and external environment can combine to generate a firm's knowledge benefit, a QCA can be applied better than a conventional analytical approach. As the variables in this study are continuous instead of binary, a fsQCA was performed using fsQCA 3.0 software (Ragin and Davey 2016).

\subsection{Calibration}

Fuzzy-set calibration is the first procedure to transform the originally observed variables into fuzzy-set membership values between 0 and 1 . Values of 1 and 0 represent full membership and full non-membership in the set, respectively, and all other scores in between have fuzzy partial membership (Zheng, Ulrich, and SendraGarcía 2021). The rules of calibration require the use of theoretical and practical knowledge for the constructs (Ragin 2008). Following Lexutt (2020) and Russo and Confente (2019), the endpoints of the 7-point Likert scales serve as the two qualitative anchors to calibrate full non-membership (i.e., value 1) and full membership (i.e., value 7), respectively, while the crossover point is calculated by observing the distribution and median score of each variable. 


\section{Results}

\subsection{Necessity Conditions}

An analysis of necessity conditions was first conducted to find whether a condition always precedes an outcome and therefore must be treated as essential (Lalicic and Weismayer 2021). In set-theoretic terms, the necessary condition is a superset of the outcome (Ragin 2008). The results of the necessity analysis are presented in Table 2. The necessary conditions procedure produces consistency and coverage scores for individual conditions (Ragin 2018). In the necessary analysis context, consistency indicates the degree to which the causal condition is a superset of the outcome, whereas coverage indicates the empirical relevance of a consistent superset (Ragin 2018). According to Ragin (2008), consistency scores of 0.9 or higher reflect necessary conditions.

As shown in Table 2, only the presence of a firm's absorptive capacity is a necessary condition for the knowledge benefit: the consistency value exceeds the recommended threshold of 0.90. This means that a firm's possession of absorptive capacity always precedes

〈Table 2〉 Analysis of Necessary Conditions.

\begin{tabular}{lcc}
\hline \multicolumn{1}{c}{ Condition } & Consistency & Coverage \\
\hline IDEATION & 0.809 & 0.966 \\
$\sim$ IDEATION & 0.252 & 0.958 \\
DEVELOP & 0.684 & 0.966 \\
$\sim$ DEVELOP & 0.374 & 0.927 \\
LAUNCH & 0.867 & 0.965 \\
$\sim$ LAUNCH & 0.197 & 0.926 \\
ABSORP & 0.954 & 0.974 \\
$\sim$ ABSORP & 0.125 & 0.946 \\
COORD & 0.890 & 0.983 \\
$\sim$ COORD & 0.198 & 0.962 \\
CUSENV & 0.757 & 0.979 \\
$\sim$ CUSENV & 0.319 & 0.944 \\
COMENV & 0.817 & 0.974 \\
$\sim$ COMENV & 0.258 & 0.949 \\
TECENV & 0.816 & 0.973 \\
$\sim$ TECENV & 0.260 & 0.952 \\
\hline Notes: IDEATION = customer participation in ideation, DEVELOP = customer participation in development, LAUNCH \\
$=$ customer participation in launch, ABSORP \\
coordination capability, CUSENV complexity of customer's needs, COMENV = competition intensity, \\
TECENV = technological turbulence. " $\sim$ indicates the negation of the condition.
\end{tabular}


knowledge benefit, and a firm's absorptive capacity is always necessary for a firm to generate knowledge benefit via customer participation. A firm's knowledge benefit via customer participation can be generated only when the firm understands and integrates external knowledge from customers. As a firm's absorptive capacity is the ability to understand and integrate external knowledge, it is impossible to create knowledge benefit using customer participation without the help of absorptive capacity. This finding is in line with Morgan, Obal, and Anokhin's (2018) contention that a firm's absorptive capacity is a necessary prerequisite for successful new products via customer participation.

Nevertheless, the results of the necessary conditions analysis reveal that single variable other than the presence of absorptive capacity is not necessary to produce a given knowledge benefit, but interwoven configurations among customer participation during different NPD stages, a firm's internal co-creation-related capabilities, and external environment are likely to lead to positive knowledge benefit.

\subsection{Sufficient Conditions}

Sufficiency means that "the outcome always occurs when the sufficient condition is present" (Lexutt 2020, p. 112) and sufficient conditions are subsets of the outcome (Ragin 2008). To analyze sufficient conditions, the minimum acceptable frequency was set to two cases per configuration given the size of the sample in this study $(N=181)$. All configurations with a minimum raw consistency of at least 0.95 and a proportional reduction in inconsistency (PRI) consistency of at least 0.95 were identified. These are well above the established 0.75 threshold (Schneider and Wagemann 2012). Table 3 reports six different roads to obtaining knowledge benefit through customer participation in NPD and depicts the alternative solutions graphically, with solid black circles indicating the presence of a variable, white circles indicating the absence (negation) of a variable and blank cells indicating that the variable is irrelevant (the don't care condition) to the outcome.

On the basis of intermediate solutions from standard analyses, the overall consistency is 0.99 and the consistency for each path configuration exceeds at least 0.99, which is well above the recommended threshold (Ragin 2006; Zheng, Ulrich, and Sendra-García 2021). High consistency scores show strong evidence that each solution and the solution as a whole are subsets of the outcome (Ragin 2018). Further, the overall coverage of 0.71 means that $71 \%$ of the outcome can be explained by these combinations of causal conditions (i.e., six solutions). The six paths meet the requirements for consistency ( $>0.75$ ) and unique coverage ( $>0.01$ ) (Schneider and Wagemann 2007).

Solution 1 shows that customer participation 
〈Table 3〉 Solutions for Building Knowledge Benefit through Customer Participation

\begin{tabular}{|c|c|c|c|c|c|c|}
\hline \multirow{2}{*}{ Configuration } & \multicolumn{6}{|c|}{ Solution } \\
\hline & 1 & 2 & 3 & 4 & 5 & 6 \\
\hline IDEATION & 0 & 0 & O & 0 & 0 & 0 \\
\hline DEVELOP & 0 & & 0 & 0 & 0 & \\
\hline LAUNCH & 0 & 0 & 0 & & 0 & 0 \\
\hline ABSORP & 0 & 0 & 0 & 0 & 0 & 0 \\
\hline COORD & 0 & 0 & 0 & 0 & ○ & 0 \\
\hline CUSENV & & O & & 0 & ○ & O \\
\hline COMENV & & ○ & 0 & 0 & 0 & 0 \\
\hline TECENV & O & O & O & 0 & O & O \\
\hline Raw coverage & 0.57 & 0.10 & 0.12 & 0.12 & 0.07 & 0.54 \\
\hline Unique coverage & 0.07 & 0.02 & 0.02 & 0.02 & 0.01 & 0.04 \\
\hline Consistency & 0.99 & 1.00 & 1.00 & 1.00 & 1.00 & 0.99 \\
\hline Solution coverage & \multicolumn{6}{|c|}{0.71} \\
\hline Solution consistency & \multicolumn{6}{|c|}{0.99} \\
\hline
\end{tabular}

Note: - indicates the presence of the condition; $\bigcirc$ indicates the absence of the condition.

Frequency cutoff: 2

Consistency cutoff: 0.99

in all the NPD stages, a firm's internal $\mathrm{co}^{-}$ creation-related capability (i.e., absorptive capacity and coordination capability), and technical turbulence are determinant factors for obtaining knowledge benefit. The conclusion has a consistency of 0.99 , and unique coverage, which refers to the proportion of the outcome explained solely by each individual solution term, is 0.07 . In Solution 2, $10 \%$ of the cases suggest that in the stable context of absence of complexity of customer needs, competition intensity, and technical turbulence, involving customers in the ideation and launch stages combined with co-creation-related capabilities achieves high knowledge benefit with a consistency of 1.00 and unique coverage of 0.02. Meanwhile, high knowledge benefit can also be achieved through the combination of customer participation in both ideation and launch stages, a firm's absorptive capacity and coordination capability, and high complexity of customer needs, competition intensity, and technical turbulence (see Solution 6); $4 \%$ of knowledge benefit is explained solely by Solution 6 .

High knowledge benefit is a product of three alternative pathways. Solution 3 suggests that weak membership in customer participation in the ideation and development phases, high membership in customer participation in the 
launch stage, high membership in a firm's internal co-creation-related capabilities, and high membership in competition intensity and technical turbulence produces knowledge benefit; consistency is 1 and unique coverage is 0.02 . Solution 4 reveals that an additional $2 \%$ of the memberships in the knowledge benefit is accounted for by the condition in which customers do not participate in the ideation and development stages and the firm has high absorptive capacity and coordination capability in the presence of high complexity of customer needs, competition intensity, and technical turbulence. Finally, 1\% of the cases accomplished knowledge benefit through the condition in which customers are involved in the ideation and launch stages but not the development stage, and the firm has an absorptive capacity but does not have coordination capability with high competition intensity and weak complexity of customer needs and technical turbulence.

\section{Discussion}

\subsection{Theoretical Implications}

The findings offer several theoretical contributions to the literature on customer participation in the NPD process. First, this study contributes to the customer participation literature by identifying six equifinal configurational paths for firms to achieve great knowledge benefit through engaging customers in the NPD process. Previous studies have empirically verified various seemingly crucial factors that influence the efficacy of customer participation in NPD (e.g., contextual factors, customer participation design factors, relationship factors, and organizational factors), focusing on the individual results of each factor on an outcome variable. However, the complex configurations among crucial factors and the ways in which they combine to generate high knowledge benefit have not yet received enough academic attention. A notable exception is the study by Zheng, Ulrich, and Sendra-García (2021), who examined configurational paths to innovation performance while simultaneously considering a firm's internal and external knowledge, its absorptive capacity, government support, and business environment. However, they did not investigate the configurational paths in the customer participation context. This study uses fSQCA, which is gaining popularity in business research, to make a novel theoretical contribution to figure out specific ways customer participation should be utilized in light of a firm's internal capabilities and external environmental turbulence.

Second, this research expands previous findings about the differential effects of involving customers in various combinations of NPD stages. Carbonell, Rodríguez-Escudero, and Pujari (2009, p. 537) pointed out that "In assessing the impact of customer involvement, 
it is important to consider the stage of the development process where customer interactions take place." Despite the need to investigate customer participation in specific combinations of NPD stages, prior researchers examined customer participation regardless of the NPD stage where customers are integrated and thus shed little light on the differential impacts of involving customers across the NPD phases. The current research addresses this research gap by analyzing all possible combinations of customer participation in various NPD stages and their influences on knowledge benefit.

Finally, the findings help resolve some inconsistent results about customer participation in the literature. As Chang and Taylor's (2016) meta-analysis on the effectiveness of customer participation revealed, integrating customer inputs into the NPD process does not always lead to positive effects; the efficacy hinges on various internal and external factors. By showing distinct but equifinal routes driving high knowledge benefit through customer participation, the current findings provide theoretical support for why the same type of customer participation leads to different outcomes.

\subsection{Managerial Implications}

The configurational results provide specific practical guidelines about what managers should do to take full advantage of customer participation and promote knowledge benefit.
First, there is no single best way to generate knowledge benefit. Instead, there are several alternative routes for the same benefit. Thus, NPD managers should first evaluate their internal co-creation-related capabilities and the degrees of complexity of customer needs, competitive intensity, and technical turbulence in their environment. They can then match the combinations of NPD stages customers are engaged in to the conditions. For example, the configurational results suggest that when technical turbulence is high and a firm is equipped with absorptive capacity and coordination capability, integrating customers across all the NPD stages could drive knowledge benefit.

Second, NPD teams are well advised to fortify their internal co-creation-related capabilities, especially absorptive capacity. A firm's internal absorptive capacity is a necessary condition for knowledge benefit. In other words, high absorptive capacity must be present for a firm to obtain knowledge benefit. Without a firm's ability to recognize, integrate, and apply external knowledge, even valuable external knowledge offered by customers is useless.

\subsection{Limitations and Further Research}

Although this research takes a configurational approach for firms to gain knowledge benefit through customer participation using a stateof-the art fsQCA and adds new insights, it also has several limitations that future researchers 
need to address. First, future researchers could expand our understanding of knowledge benefit via customer participation by considering the type and sequence of created knowledge benefit. Given that the focus of this paper is on the configurational effects among various factors leading to knowledge benefit, the possibility has not been considered that different types of knowledge benefit (e.g., needs-related vs. solution-related) could be generated by various combinations of relevant factors and distinct knowledge benefit could emerge sequentially. For example, a combination of involving customers in the ideation stage in the environment where customer needs are highly complex may generate needs-related knowledge benefit, whereas a firm's involvement of customers in the development stage with high absorptive capacity and coordination capability may lead to solution-related knowledge benefit. Further, distinct types of knowledge benefit may emerge sequentially (e.g., needsrelated knowledge benefit is generated first and then solution-related knowledge benefit is created later). Thus, these possibilities for different types and sequences of knowledge benefit provide future researchers with interesting topics.

Second, future researchers are advised to take into account critical factors other than a firm's internal co-creation-related capabilities and external environmental turbulence. In the customer participation context, a firm's internal capabilities and external environment have been regarded as key factors to determine the effect of customer participation. However, relationship factors such as prior relationship and interdependence between customers and the firm, as well as organizational support factors such as organizational culture (e.g., openness, innovative culture) may also influence how customer participation generates knowledge benefit in NPD. Thus, additional configurational exploration to consider relationship factors and organizational support factors may add new insights about alternative paths for knowledge benefit.

Lastly, future researchers need to check the robustness of the calibration of the measures. In this study, all the measures of the key factors are based on a 7-point Likert or rating scale. Although the measures are carefully calibrated following the suggestions on how to calibrate a 7-point scale in the fsQCA (Lexutt 2020; Russo and Confente 2019), different ways to calibrate the 7 -point scale may lead to different results. Therefore, it is suggested that future researchers employ various ways of calibrating a 7-point scale on the basis of theoretical and practical knowledge for the constructs.

〈Received June 9. 2021〉

〈Revised June 28. 2021〉

$\langle$ Accepted July 5. 2021〉 


\section{References}

Carbonell, Pilar, Ana I. Rodríguez-Escudero, and Devashish Pujari (2009), "Customer Involvement in New Service Development: An Examination of Antecedents and Outcomes," Journal of Product Innovation Management, 26(5), 536-550.

Chang, Woojung (2019), "the Joint Effects of Customer Participation in Various New Product Development Stages," European Management Journal, 37(3), 259-268.

Chang, Woojung and Steven A. Taylor (2016), "The Effectiveness of Customer Participation in New Product Development: A MetaAnalysis," Journal of Marketing, 80(1), 47-64.

Cohen, Wesley. M. and Daniel A. Levinthal (1990), “Absorptive Capacity: A New Perspective on Learning and Innovation," Administrative Science Quarterly, 35(1), 128-152.

De Luca, Luigi M. and Kwaku Atuahehe-Gima (2007), "Market Knowledge Dimensions and Cross-Functional Collaboration: Examining the Different Routes to Product Innovation Performance," Journal of Marketing, 71(1), 95-112.

Fang, Eric (Er) (2008), "Customer Participation and the Trade-Off between New Product Innovativeness and Speed to Market," Journal of Marketing, 72(4), 90-104.
Fang, Eric, Robert W. Palmatier, and Kenneth R. Evans (2008), "Influence of Customer Participation on Creating and Sharing of New Product Value," Journal of the Academy of Marketing Science, 36, 322-336.

Fiss, Peer C. (2011), "Building Better Causal Theories: A Fuzzy Set Approach to Typologies in Organization Research," Academy of Management Journal, 54(2), 393-420.

Gruner, Kjell E. and Christian Homburg (2000), "Does Customer Interaction Enhance New Product Success?" Journal of Business Research, 49, 1-14.

Im, Subin and John P. Workman Jr. (2004), "Market Orientation, Creativity, and New Product Performance in High-Technology Firms," Journal of Marketing, 68(2), 114132.

Jaworski, Bernard H. and Ajay K. Kohli (1993), "Market Orientation: Antecedents and Consequences," Journal of Marketing, 57 (3), 53-70.

Jayachandran, Satish, Kelly Hewett, and Peter Kaufman (2004), "Customer Response Capability in a Sense-and-Respond Era: The Role of Customer Knowledge Process," Journal of the Academy of Marketing Science, 32(3), 219-233.

Joshi, Ashwin and Sanjay Sharma (2004), "Customer Knowledge Development: Antecedents and Impact on New Product Performance," Journal of Marketing, 68 
(4), 47-59.

Katz, Ralph and Thomas J. Allen (1985),

"Organizational Issues in the Introduction of New Technologies," in The Management of Productivity and Technology in Manufacturing, P.R. Kleindorfer, ed. New York: Plenum Press, 275-300.

Kollmann, Tobias, Christoph Stöckmann, Thomas Niemand, Simon Hensellek, and Katharina de Cruppe (2021), “A Configurational Approach to Entrepreneurial Orientation and Cooperation Explaining Product/Service Innovation in Digital vs. Non-digital Startups," Journal of Business Research, 125, 508-519.

Lalicic, Lidija and Christian Weismayer (2021), “Consumers' Reasons and Perceived Value Co-creation of Using Artificial Intelligenceenabled Travel Service Agents," Journal of Business Research, 129, 891-901.

Lee, Hyun Jung, Jeong Eun Park, and Jae Hyun Pae (2015), "How to Build a Learning Capability for Innovation? A Framework of Market-Based Learning Process," Asia Marketing Journal, 17(1), 27-53.

Li, Yinnan, Jongsung Kim, and Young Woo Lee (2020), "Marketing Knowledge Management and Innovation Performance: Examining the Moderating Role of Business Environmental Volatility," Asia Marketing Journal, 22(3), 51-69.

Lim, Sejeong (2019), “Developing Cars through Customer Participation, i30 N line and
Veloster 'Customer Fit', Kookminilbo, accessed by [http://news.kmib.co.kr/ article/view .asp? arcid $=0013448119 \&$ code $=61141111 \& \operatorname{sid} 1=i]$.

Lexutt, Eva (2020), “Different Roads to Servitization Success-A Configurational Analysis of Financial and Non-financial Service Performance," Industrial Marketing Management, 84, 105-125.

Mahr, Dominik, Annouk Lievens, and Vera Blazevic (2014), "The Value of Customer Cocreated Knowledge during the Innovation Process," Journal of Product Innovation Management, 31(3), 599-615.

Moorman, Christine and Anne S. Miner (1997), "The Impact of Organizational Memory on New Product Performance and Creativity," Journal of Marketing, 34(1), 91-106.

Morgan, Todd, Sergrey Anokhin, and Joakim Wincent (2019), “New Service Development by Manufacturing Firms: Effects of Customer Participation under Environmental Contingencies," Journal of Business Research, 104(11), 497-505.

Morgan, Todd, Michael Obal, and Sergrey Anokhin (2018), “Customer Participation and New Product Performance: Towards the Understanding of the Mechanisms and Key Contingencies," Research Policy, 47(2), 498-510.

Morgan, Todd, Michael Obal, and Robert D. Jewell (2021), "Strategic Change and Innovation Reputation: Opening Up the 
Innovation Process," Journal of Business

Research, 132, 249-259.

Nambisan, Satish (2002), “Designing Virtual Customer Environments for New Product Development: Toward a Theory," Academy of Management Review, 27(3), 392-413.

Poetz, Marion K. and Martin Schreier (2012), "The Value of Crowdsourcing: Can Users Really Compete with Professionals in Generating New Product Ideas?" Journal of Product Innovation Management, 29 (2), 245-256.

Ragin, Charles C. (2006), "Set Relations in Social Research: Evaluating Their Consistency and Coverage," Political Analysis, 14(3), 291-310.

Ragin, Charles C. (2008), Redesigning Social Inquiry: Fuzzy Sets and Beyond, University of Chicago Press.

Ragin, Charles C. (2018), User's Guide to Fuzzy-Set/Qualitative Comparative Analysis 3.0. Irvine, California: Department of Sociology, University of California.

Ragin, Charles C. and Sean Davey (2016), Fuzzy-Set/Qualitative Comparative Analysis 3.0. Irvine, California: Department of Sociology, University of California.

Russo, Ivan and Ilenia Confente (2019), "From Dataset to Qualitative Comparative Analysis (QCA)-Challenges and Tricky Points: A Research Note on Contrarian Case Analysis and Data Calibration, Australasian Marketing Journal, 27, 129-135.
Schneider, Carsten Q. and Claudius Wagemann (2007), Qualitative Comparative Analysis (QCA) und Fuzzy Sets, Leverkusen: Barbara Budrich.

Schneider, Carsten Q. and Claudius Wagemann (2012), Set-theoretic Methods for the Social Sciences - A Guide to Qualitative Comparative Analysis, Cambridge University Press.

Son, Insoo, Jong-Ho Lee, and Dongwon Lee (2018), "Examining Decision-Making of Participating in Open Innovation Platform," Asia Marketing Journal, 19(4), 61-85.

Wang, Liwen, Jason Lu Jin, Kevin Zheng Zhou, Caroline Bingxin Li, and Eden Yin (2020), "Does Customer Participation Hurt New Product Development Performance? Customer Role, Product Newness, and Conflict," Journal of Business Research, 109, 246-259.

Woodside, Arch G., Eunju Ko, and TzungCheng (T.C.) Huan (2012), "The New Logic in Building Isomorphic Theory of Management Decision Realities," Management Decision 50(5), 765-777.

Zheng, Lu, Klaus Ulrich, and Javier SendraGarcía (2021), "Qualitative Comparative Analysis: Configurational Paths to Innovation Performance," Journal of Business Research, 128, 83-93. 